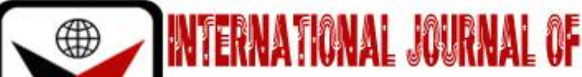

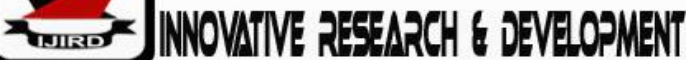

ISSN 2278 - 0211 (Online)

\section{Innovative Methods in Delivering Pre-Exposure Prophylaxes Services for Adolescent Girls and Young Women: Outcomes from the Consumer Demand - Driven Project in Nairobi County, Kenya}

Simon Sedaula Mwangi
Program Manager, Department of Health,
Bar Hostess Empowerment and Support Program (BHESP), Kenya
Mercy Mutonyi
Program Coordinator, Department of Health,
Bar Hostess Empowerment and Support Program (BHESP), Kenya
Penina W Mwangi
Executive Director, Department of Organisational,
Bar Hostess Empowerment and Support Program (BHESP), Kenya
Judy Mwangi Maundu
Consultant, Department of Public Health, MaReSol Consulting, Kenya

\begin{abstract}
:
Background: There is high HIV prevalence among adolescent girls and young women (AGYW) aged 15-24years, accounting for $21 \%$ of 88,000 new HIV infections in Kenya. With funding from the US Department of State (DOS), BHESP implemented a two-year project to deliver Pre-Exposure Prophylaxis (PrEP) for AGYW in Nairobi. The objective of the evaluation was to establish effectiveness of the innovation in raising demand and expanding access to PrEP.

Methods: A mixed-method study design was applied, utilising quantitative and qualitative data. A random sample of 213 AGYW took part in a satisfaction survey, while semi-structured focus group discussions (FGDs) were carried out with AGYW and peer educators. Review of program secondary data was also done. Quantitative data was analysed using MS Excel, while thematic analysis applied for qualitative data.

Results: BHESP reached 30,455 community members with HIV and PrEP information, majority of whom were females (67.2\%). HIV counselling and testing was done for 29,241 community members, comprising 17,834 (70.0\%) AGYW. Of these, 5126persons were newly enrolled in PrEP, including 4957 (97.8\%) AGYW. Barriers to access and continuation of services were side effects; 110 (55.6\%) and time constraints; 102 51.8\%. Enabling factors were reminders calls from service providers; 147 (72\%) and risk reduction; 147 (72\%). Satisfaction levels was high, with 208 (98.6\%) of expressing overall satisfaction, specifically in enrolment process; 192(90.3\%), service delivery; 194 (90.9\%), and quality of services; 198 (92.8\%).

Conclusion: The innovation was successful in raising awareness and enhancing uptake of PrEP. Profiling and follow-up of AGYW are critical in defining and tracking continuation. We recommend further insights gathering on factors affecting PrEP continuation and the most effective ways of involving males to catalyse overall success.
\end{abstract}

Keywords: Adolescent girls and young women, pre-exposure prophylaxis, consumer demand driven, youth- friendly, continuation

\section{Background}

The number of new HIV infection among adolescent girls and young women (AGYW) in sub-Saharan Africa remains exceptionally high, with 4500 new infections recorded in 2015 [1]. Although HIV in Kenya is generalized at a prevalence of $5.6 \%$ among the general adult population, the indicators are poorer among young people. With a national HIV prevalence estimates of $2.5 \%$ amongst the AGYW (2017), this figure is three times that of their male counterparts; coupled with $21 \%$ the total number of all new HIV infections [2]. The High HIV incidence among young women in Africa highlights the need for urgent scale-up of proven female-controlled HIV prevention strategies. Social, structural, and economic disparities perpetuate vulnerabilities of women. The lower social and economic power of women makes it difficult for them to negotiate safe sex. In stable partnerships, condom use is low, and women are often unaware of their partner's HIV status [3]. 
The World Health Organisation (WHO) (2015) recognised that pre-exposure prophylaxis (PrEP) had potential in reducing HIV infections at for the general population and released new guidelines and a policy brief recommending that PrEP be offered as a choice to people at substantial risk of HIV infection as part of a combination HIV prevention programme [4]. The recommendation specified supporting of use of Tenofovir containing (PrEP) to prevent the acquisition of HIV [5] . PrEP was previously recommended only for key affected populations such as sex workers, men who have sex with men (MSM) and people who inject drugs (PWID) [6]. Antiretroviral pre-exposure prophylaxis (PrEP) is an option for women that do not require negotiation for safer sex. Thus, successful delivery of PrEP for HIV prevention, at scale and tailored to the epidemiologic profile of priority populations, has the potential to reverse the global epidemic [7]

Generally, UNAIDS defines priority populations for PrEP as groups with an HIV incidence of about 3 per 100 personyears or higher. Gender inequalities, including gender-based violence, exacerbate women's and girls' physiological vulnerability to HIV and block their access to HIV services. Young people are denied the information and the freedom to make free and informed decisions about their sexual health, with most lacking the knowledge required to protect themselves from HIV. The impact of these barriers is strongest in high-prevalence settings, predominantly in eastern and southern Africa [8].

Evidence generated through PrEP trials shows that, when taken consistently and correctly, PrEP is very effective in reducing the risk of HIV infection from unprotected sex by over 90\% [9]. The Partners PrEP trial recruited 4,758 heterosexual couples in which one partner was living with HIV across Kenya and Uganda. The risk of HIV infection was reduced by $62 \%$ among those who took tenofovir and $73 \%$ among those who received Truvada [10].

The United Nations General Assembly's 2016 Political Declaration on HIV and AIDS includes a commitment to providing three million people at higher risk of HIV infection with PrEP by 2020. However, as of October 2016, just 100,000 people were enrolled on it. Most people on PrEP live in the USA, although a significant number of people across the world are also thought to be accessing it through the internet. Considerable additional effort will be needed to attain the new global target of reaching three million people at substantial risk of HIV infection with PrEP by 2020 [1].

Working in Kenya, Lesotho, Malawi, Mozambique, South Africa, eSwatini, Tanzania, Uganda, Zambia and Zimbabwe, PEPFAR's DREAMS initiative is also supporting adolescent girls and young women who are at high risk of HIV to access PrEP. By the end of 2017, DREAMS aimed to reach 10,500 adolescent girls and young women with initiation and adherence services for the intervention [11]. Currently, programmatic scale-up of pre-exposure prophylaxis (PrEP) is progressing with nearly 400,000 PrEP initiations worldwide as of October 2018 [12]

A study of 2,120 women from Kenya, Tanzania, and South Africa found that despite all participants having been identified as being of heightened HIV risk, around half of those enrolled in the study thought they had 'no chance'of acquiring HIV in the next 12 weeks. This meant they were unlikely to initiate or adhere to PrEP despite being given access to it. To combat this, the study suggested integrating HIV risk assessment and PrEP dispensation into established sexual and reproductive health services, including HIV/STI testing and counselling, antenatal care, and contraceptive counselling, which women access routinely [13]. Several factors were attributed to this difference in adherence levels including knowledge and awareness of PrEP, its availability and the participants' lifestyle [14].

Another factor which can affect adherence is exposure to abuse and violence within a relationship. A study carried out among mixed status couples across Africa found that women who had experienced verbal, physical, or economic abuse from a partner were more likely to have low PrEP adherence. The reasons given included stress and forgetting, leaving home without pills, and partners throwing pills away [15]. In some settings, PrEP is associated with high-risk sexual activity. It also has the stigma of being related to HIV (which may also relate to other stigmas, such as homosexuality, sex work, and/or drug use) and the stigma of PrEP being an alternative to condoms, since condom use is often associated with responsible sexual activity [16].

In July 2016, the Ministry of Health in Kenya released 'Guidelines on use of Antiretroviral Drugs for Treating and Preventing HIV infections in Kenya', recommending immediate initiation onto ART and the Provision of PrEP to all people at substantial ongoing risk of Acquiring HIV infection [17]. The Bar Hostess Empowerment and Support Program (BHESP) was involved in the PrEP demonstration project (2015) and learnt that PrEP held great potential in contributing to the UNAIDS 90-90-90 target through advocating and championing PrEP delivery as part of its youth-friendly HIV prevention programs.

Through DREAMS Innovation Challenge, funded by the United States Department of State (DOS) and managed by JSI Research \& Training Institute, Inc. (JSI), BHESP implemented a two and half years project (2017-2019) grounded on a 'Consumer Demand-Driven PrEP for Adolescent Girls and Young Women (AGYW)' model to enroll PrEP as an additional prevention choice for the AGYW at substantial ongoing risk of HIV infection, as part of the combination prevention approaches within a context of integrated youth- friendly Sexual Reproductive Health (SRH).

The key messaging to consumers entailed an emphasis on the benefits of the commodity (PrEP) to create and sustain demand, while implementation strategies espoused use of radio shows, social media, musical events, PrEP champions \& celebrities to raise awareness, peer educators to serve as the link between the communities, the AGYW \& service providers. Behavioral risk factors, encompassing intimate partner violence (IPV), were assessed using a standardized risk assessment tool ${ }^{20}$ and the AGYW who were found eligible and accepted to be enrolled in PrEP were initiated on PrEP on the same day.

Each of the AGYW was assigned to a peer educator to provide continued support and follow up and ensure the AGYW stayed on PrEP. Support groups and adherence meetings served as platforms where AGYW discussed success and challenge factors in use of PrEP. The overall target was to reach 10,000 AGYW with HTS and 6000 AGYW with PrEP in Nairobi County, Kenya.The project was implemented through three BHESP donor-supported Drop-in Centers (DICEs) comprising Kariobangi, Jogoo road and Karasani, all in Nairobi, in partnership with the Department of Health, Nairobi County and the National AIDS and STI Control Programme (NASCOP). 
With the project ending in March 2019, BHESP carried out an outcomes study to establish the effectiveness of the consumer demand-driven approach in raising demand and expanding access to PrEP for the AGYW, in order to generate recommendations to better inform improvements for programmers and policy makers.

\section{Methods}

A cross-sectional study approach was applied, using mixed methods in data collection to maximize triangulation. A satisfaction survey was done with AGYW to get the overall feedback on the quality of services provided at the service delivery points. Using a semi structured interview guide, focused group discussions (FGDs) were held with the AGYW peer educators and community leaders to get an in-depth understanding of the factors affecting PrEP awareness, facilitators and barriers in PrEP utilization.

Desktop review of secondary data sourced from project reports served to determine the overall reach and project outcomes. Systematic random sampling was applied, using the PrEP services register and the list of peer educators. The summary study approach to data collection approach, tools, respondents and sample size is summarized in table 1.0;

\begin{tabular}{|c|c|c|c|}
\hline $\begin{array}{l}\text { Data Collection } \\
\text { Approach/Tool }\end{array}$ & Unit of Analysis & Sample Size & Information Expected \\
\hline $\begin{array}{l}\text { Structured } \\
\text { survey }\end{array}$ & $\begin{array}{l}\text { AGYW reached with } \\
\text { PrEP information, } \\
\text { enrolled in PrEP }\end{array}$ & 243 & $\begin{array}{l}\text { Satisfaction with services } \\
\text { and feedback for } \\
\text { improvement }\end{array}$ \\
\hline FGD guide & $\begin{array}{l}\text { AGYW reached with } \\
\text { PrEP information, } \\
\text { enrolled in PrEP for } \\
\text { the over one year }\end{array}$ & $\begin{array}{l}3 \text { FGDs (10 girls each) - One } \\
\text { for each of the } 3 \text { BHESP } \\
\text { service delivery point }\end{array}$ & $\begin{array}{c}\text { Challenges impeding PrEP } \\
\text { uptake and } \\
\text { recommendations to } \\
\text { improve PrEP services } \\
\end{array}$ \\
\hline FGD guide & $\begin{array}{c}\text { Peer educators } \\
\text { working with AGYW }\end{array}$ & $\begin{array}{c}3 \text { FGDs (6 peer educators } \\
\text { each) }\end{array}$ & $\begin{array}{c}\text { Experiences as a peer } \\
\text { educators and lesson learnt }\end{array}$ \\
\hline $\begin{array}{l}\text { Desktop review } \\
\text { of program } \\
\text { documents }\end{array}$ & $\begin{array}{l}\text { Project processes and } \\
\text { results indicators }\end{array}$ & $\begin{array}{l}\text { Project proposal, work/M\&E } \\
\text { plans, quarterly/annual } \\
\text { reports }\end{array}$ & $\begin{array}{l}\text { Project outputs and } \\
\text { outcomes, challenges and } \\
\text { recommendations }\end{array}$ \\
\hline
\end{tabular}

Table 1: Overall Study Approach

Ethical clearance was obtained from both International (JSI) and Local (AMREF) Institutional Review Boards. The study participants were interviewed only after signing theDREAMS IC standard consent form. For confidentiality, the names of the respondents were not required on the tools, the tools were coded, and data analysis anonymized. Qualitative data was and analyzed using a thematic framework in line with the program logic, whereas quantitative data was processed using SPSS 17.0.

\section{Results}

Through BHESP's youth-responsive AGYW-led strategies (for instance radio and musical shows), the project reached 30,455 persons with HIV and PrEP information, majority of whom were females, 28930 (95\%) while the rest were males. HIV counselling and testing was done for 29,241 persons, of which 28,930 were women in various age categories and the few remaining were male 311. Out of all the women, 17,834 were AGYW(61.4\%), while the rest were female aged $25+$ years. Positive tests were obtained in 213 of all the women that were tested $(0.74 \%)$, while none of the males was positive. A breakdown of the age categories, by number of women receiving HTS and the tests' results are summarised in table 2.0.

\begin{tabular}{|c|c|c|c|c|}
\hline Age category & $\begin{array}{c}\text { No. received HTS } \\
\text { and counselling }\end{array}$ & $\begin{array}{c}\text { \% of total HIV } \\
\text { testing done }\end{array}$ & $\begin{array}{c}\text { No. of Positive } \\
\text { results (\%) }\end{array}$ & $\begin{array}{c}\text { \% with positive } \\
\text { results }\end{array}$ \\
\hline AGYW 15-19 & 5864 & 20.3 & 37 & 0.62 \\
\hline AGYW 20-24 & 11970 & 41.4 & 76 & 0.63 \\
\hline Female 25+ & 11096 & 38.4 & 100 & 0.90 \\
\hline Total & 28930 & 100.0 & 213 & 0.74 \\
\hline
\end{tabular}

Table 2: HTS delivered for women and girls by age categories and tests' results

Using the Government's risk assessment screening tool (RAST),17,834 AGYW wereassessed to determine PrEP eligibility. As a result, 5126persons were newly enrolled to PrEP, of which, 4957 (96.7\%) were AGYW, while the rest were women aged $25+$ years and males. This is detailed in table 3.0. 


\begin{tabular}{|c|c|c|c|}
\hline Sex & Age category & Newly enrolled on PrEP & Percent \\
\hline \multirow{2}{*}{ Female (AGYW) } & $15-19$ & 1745 & 34.0 \\
\cline { 2 - 4 } & $20-24$ & 3212 & 62.7 \\
\hline Female & $25+$ & 112 & 2.2 \\
\hline Male & $15-49$ & 57 & 1.1 \\
\hline \multicolumn{2}{|r|}{ Total } & 5126 & 100.0 \\
\hline
\end{tabular}

Table 3: Total and Proportion of Persons Enrolled on Prep

In addition to the new PrEP re-enrolment, 3048 received PrEP revisits services (refills), over the life of project, which were done on monthly or quarterly bases. PrEP continuation (adherence) at three months post enrolment was recorded at $45 \%$, while at six months the figure came down to $36 \%$.

In the course of enrolling for PrEP, BHESP sought to find out if the AGYW had experienced any form of genderbased violence (GBV), a factor that has been shown to predict increase risk to HIV infection. In total, 887 AGYW (17.3\%)were affirmative. When this was subcategorised, the occurrence in the ages 15 -19 years was 344 (19.7\%) and 543 $(16.9 \%)$ for those in the age categories of 20-24 years old. 4 cases below 15 years were excluded from the analysis.

Of the total reporting occurrence of GBV, 274 (31\%) cited physical violence, while 180 (20\%) reported sexual violence and the rest 433 (49\%) experienced either emotional or psychological abuse.

To establish the satisfaction levels with the services delivered through the BHESP'sdrop-in centres (DICEs), a survey was conducted with 213 AGYW, most of whom had been with the project for at least two years. This was combined by three focus group discussions with the AGYWto get in-depth information on the quality of the service delivered to them. To provide further insight, three more FGDs were held with peer educators whose role was to support the AGYW in all stages of implementation.

Most of the AGYW learnt about PrEP through the radio; 91(43\%), peer educator;45(21\%), friends28(13\%); social media; 23 (11\%); and the rest;26 (12\%) got the information from other means, consisting of musical shows, road shows and referral from other implementing partners. When asked if they were aware of their HIV status, 187 (88\%) were affirmative. Of these, 155 (83\%) got to know of their HIV status through the project, while the rest had known their status before enrolling in the project.

The FGDs with the AGYW showed that they got information from all the media of communication utilised by BHESP except referral from other partners. In addition, the football matches held during the International Women's Day (IWD) and the routine clinic visit to get other services from the DICE's were quoted to have raised awareness of PrEP in some of the AGYW.

As seen in figure1.0, the AGYW participating in the survey had received a wide range of services in the health drop in centre, the highest being information on HIV/PrEP/SRH; 210 (98.6\%), HIV testing; 209 (98.1\%) psychosocial support; 203 (95.3\%) and PrEP medication; 197(92.5\%).

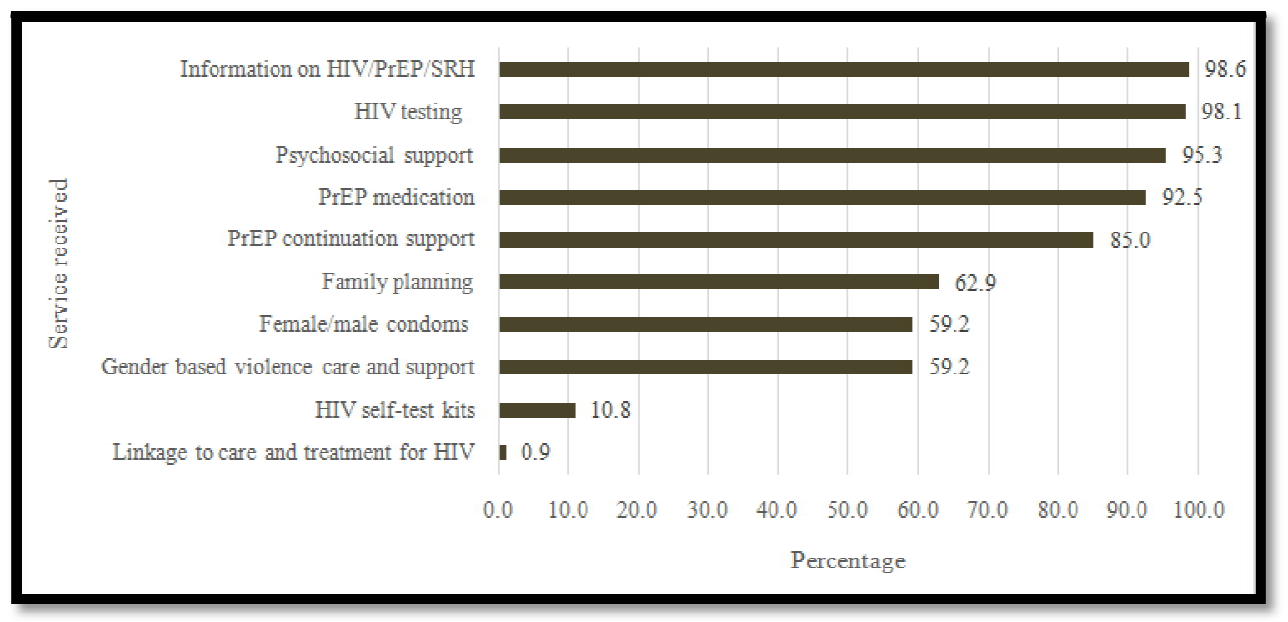

Figure 1: Services Received by the AGYW

The satisfaction scores were in form of a 5-point Likert scale, with the highest satisfaction ranked as 'very satisfied' and the lowest satisfaction ranked as 'very dissatisfied'. Scores were indicated only where the response applied, since not all the AGYW had participated in every activity or received all the services. The scores ranged from 67 to 213 AGYW.

As seen in table 4.0, the overall satisfaction levels with the project was very high with 208 (98.6\%) of AGYW indicating that they were either very satisfied or satisfied. Enrolment in the project also scored a high average satisfaction level $90.3 \%$ in the various channels used to raise awareness and create demand, including musical shows, social media and radio shows. A similar average rating was obtained in services delivery (90.9\%), comprising twelve services provided to the AGYW, key being information on PrEP enrolment (98.4\%), HIV and SRH (98.0\%), HIV testing (96.6\%), and psychosocial support (92.9\%). Quality of services, which consisted of satisfaction with the courtesy, friendliness, and professionalism of peer educators \& the services providers also rated highly in satisfaction, with an average score of 92.8\%. 
When satisfaction for specific services were considered HIV self-test kits and condoms generated the lowest level of satisfaction, relative to other services as follows; provision of HIV self-test kits $68.6 \%$ and use of HIV self-test kits; $52.1 \%$.

\begin{tabular}{|c|c|c|c|c|c|c|c|c|c|c|}
\hline $\begin{array}{c}\text { Satisfaction } \\
\text { components } \\
\text { (n) as applicable } \\
\end{array}$ & $\begin{array}{c}\text { Very } \\
\text { Satisfied } \\
\text { (n) } \\
\end{array}$ & $\%$ & $\begin{array}{l}\text { Satisfied } \\
\text { (n) }\end{array}$ & $\%$ & $\begin{array}{l}\text { Neutral } \\
\text { (n) }\end{array}$ & $\%$ & $\begin{array}{l}\text { Dissatisfied } \\
\text { (n) }\end{array}$ & $\%$ & $\begin{array}{c}\text { Very } \\
\text { Dissatisfied } \\
\text { (n) } \\
\end{array}$ & $\%$ \\
\hline \multicolumn{11}{|c|}{ Enrolment in the project } \\
\hline $\begin{array}{c}\text { Musical events to } \\
\text { sensitize AGYW } \\
\text { (169) }\end{array}$ & 102 & 60.4 & 54.0 & 32.0 & 6.0 & 3.6 & 6.0 & 4.0 & 0 & 0 \\
\hline $\begin{array}{l}\text { Radio shows to raise } \\
\text { awareness (193) }\end{array}$ & 156 & 80.2 & 34 & 17.6 & 2 & 1.0 & 1 & 0.5 & 0 & 0.0 \\
\hline $\begin{array}{c}\text { Social media } \\
\text { (Tweeter) to raise } \\
\text { awareness (109) } \\
\end{array}$ & 75 & 68.8 & 23 & 11.9 & 8 & 7.3 & 1 & 0.9 & 2 & 1.8 \\
\hline \multicolumn{11}{|c|}{ Service delivery } \\
\hline $\begin{array}{c}\text { General } \\
\text { HIV/PrEP/SRH } \\
\text { information }(210)\end{array}$ & 194 & 92.3 & 12 & 5.7 & 2 & 1.0 & 1 & 0.5 & 1 & 0.5 \\
\hline $\begin{array}{c}\text { Screening for PrEP } \\
(209)\end{array}$ & 189 & 90.4 & 17 & 8.1 & 1 & 0.5 & 1 & 0.5 & 1 & 0.5 \\
\hline $\begin{array}{c}\text { HIV testing and } \\
\text { counselling (209) }\end{array}$ & 193 & 92.3 & 9 & 4.3 & 3 & 1.4 & 3 & 1.4 & 1 & 0.5 \\
\hline $\begin{array}{c}\text { Response to GBV } \\
(126)\end{array}$ & 123 & 97.7 & 3 & 2.3 & 0 & 0.0 & 0 & 0.0 & 0 & 0.0 \\
\hline $\begin{array}{c}\text { Enrollment to PrEP } \\
(190)\end{array}$ & 179 & 94.2 & 8 & 4.2 & 2 & 1.1 & 1 & 0.5 & 0 & 0.0 \\
\hline PrEP refill (65) & 58 & 89.2 & 6 & 9.2 & 0 & 0.0 & 1 & 1.5 & & \\
\hline $\begin{array}{l}\text { PrEP continuation } \\
\text { meetings (187) }\end{array}$ & 151 & 80.7 & 12 & 6.4 & 9 & 4.8 & 8 & 4.3 & 7 & 3.7 \\
\hline $\begin{array}{l}\text { Use of SMS as } \\
\text { reminders for } \\
\text { appointment for } \\
\text { refills (190) }\end{array}$ & 93 & 48.9 & 75 & 39.5 & 17 & 8.9 & 5 & 2.6 & 0 & 0.0 \\
\hline $\begin{array}{l}\text { Monthly focus group } \\
\text { discussions in the } \\
\text { safe spaces (183) }\end{array}$ & 151 & 82.5 & 19 & 10.4 & 6 & 3.3 & 4 & 2.2 & 3 & 1.6 \\
\hline $\begin{array}{l}\text { Provision of self-test } \\
\text { kits (23) }\end{array}$ & 15 & 65.2 & 3 & 13.4 & 0 & 0 & 2 & 10.4 & 3 & 13.0 \\
\hline $\begin{array}{l}\text { Use of self-test kits } \\
\text { with partners (20) }\end{array}$ & 7 & 35.0 & 4 & 20.0 & 4 & 20.0 & 4 & 20.0 & 1 & 5.0 \\
\hline $\begin{array}{c}\text { Provision of } \\
\text { condoms (210) }\end{array}$ & 165 & 78.6 & 13 & 6.2 & 0 & 0.0 & 16 & 7.6 & 0 & 0.0 \\
\hline \multicolumn{11}{|c|}{ Quality of the service } \\
\hline $\begin{array}{c}\text { Courtesy, } \\
\text { friendliness, and } \\
\text { professionalism of } \\
\text { peer educators } \\
(213)\end{array}$ & 178 & 83.6 & 22 & 10.3 & 9 & 4.2 & 2 & 0.9 & 2 & 0.9 \\
\hline $\begin{array}{l}\text { Courtesy, } \\
\text { friendliness, and } \\
\text { professionalism of } \\
\text { DICE service } \\
\text { providers (209) }\end{array}$ & 194 & 92.8 & 12 & 5.7 & 1 & 0.5 & 1 & 0.5 & 1 & 0.5 \\
\hline $\begin{array}{c}\text { Project's overall } \\
\text { performance (211) }\end{array}$ & 201 & 95.3 & 7 & 3.3 & 3 & 1.4 & 0 & 0.0 & 0 & 0.0 \\
\hline
\end{tabular}

Table 4:Satisfaction with various project components

The AGYW participating in the FGDs cited three areas as most satisfying, entailing; a) Musical events, as this were fun, allowed AGYW to interact with celebrities, and presented an opportunity to get HTS services; b) Support group meetings, as these were also fun and promote sharing information on issues like sexually transmitted diseases and economic empowerment; c) Response to GBV - the legal aid clinic was informative and it provided knowledge on different types of violence which they did not know about, and guidance on how to report GBV.

'The advantage with the DICEs is that the service providers are young and understand you, unlike in other facilities where you find 'wazae', (meaning elderly service providers), who ask many irrelevant questions, like 'why do you want family planning?' or PrEP services. The don't give adequate information for services that one needs. The clinics close early, and the services are not provided in one 
place, so one is required to move from one place to the other. One also has to pay for some of the services and it is costly'- $A G Y W$

The opinion from the FGD with the peer educators mirrored the AGYW responses, citing musical events, response to GBV and safe space discussions.

'Through participating in this project, I now can avoid getting prevent pregnancy and HIV at the same time, the different kinds of HIV services available; I have earnt about correct condom use and has not experienced condom burst of late; I have been able to continue using PrEP using the advice provided by the service providers and peer educators; and we now know that we can easily get of health services through a clinic and not just buying drugs over the counter' - AGYW

From the peer educator's perspective, the musical event was the was the best of demand creation mechanisms, as the platform allowed to several activities that were fun to the AGYW to take place for instance, singing, dancing and modelling competition, and interacting with celebrities. In the process the project was able to provide information on HIV prevention and SRH information, conduct HIV testing.

'We heard about PrEP for the first time on radio and some us participated in the radio shows to share our experience in PrEP services. Through the project, we now know how to recognise and report GBV cases and understand our human rights, which we did not know before' - Peer Educator

The study sought to find out from the AGYW using PrEP the factors that motivated them to stay on PrEP. Out of the 197 AGYW who are using or have been on PrEP,142 (72.1\%) were motivated by the need to stay safe from HIV infection and similar proportion cite the phone calls from the services provider. The rest of the details are presented in figure 2.0; The FGDs resonated the barriers, top of which was the distance, side effects and stigma.

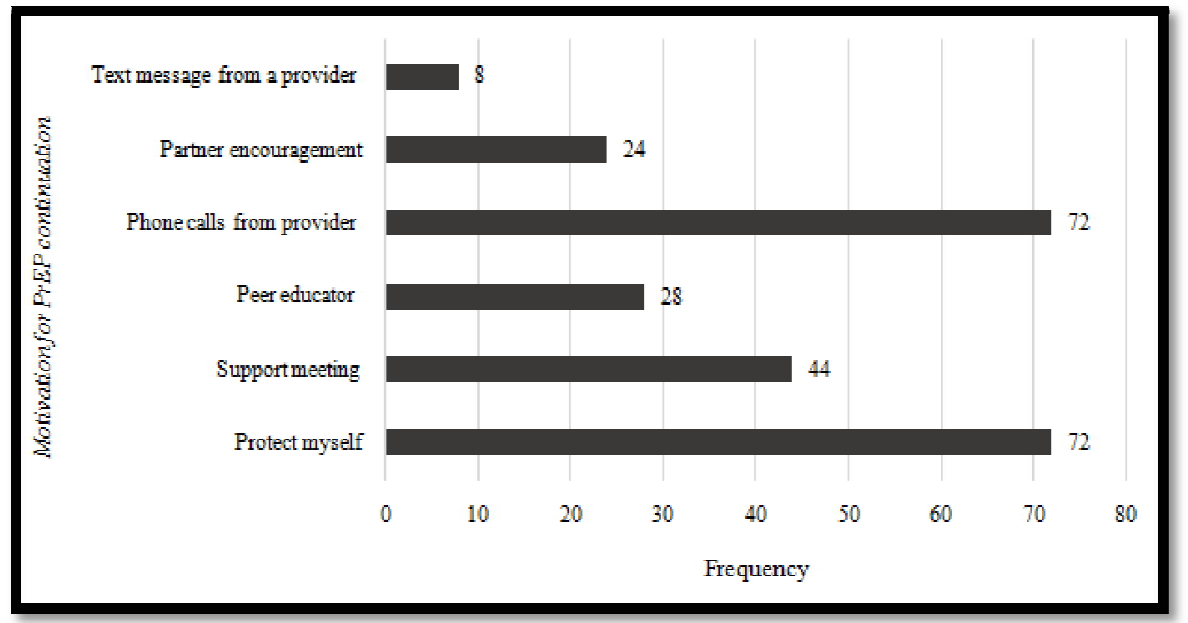

Figure 2: Reasons that motivated AGYW to continue using PrEP

When asked what the most challenging component in had been accessing and continuation of PrEP, services, most of the AGYW cited side effects (55.6\%), time constraints (51.8\%) distance from the DICE (37.1\%). Figure 3.0 provides more details; The FGDs resonated the barriers, top of which was the distance, side effects and stigma.

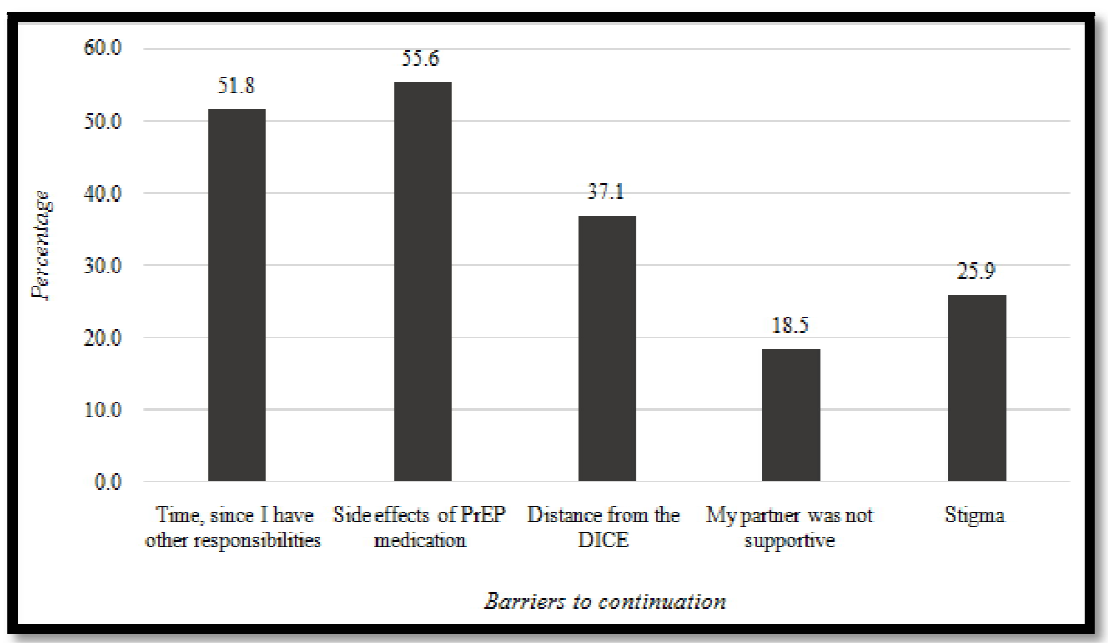

Figure 3: Barriers to continuation of PrEP medication 
What prevents us from continuing with PrEP are distance to the clinics and time, side effects, forgetting and fear of stigma and discrimination. You have to take it in private, not in front of people and sometimes this is not possible. PrEP and peer support were not available at times when needed $A G Y W$

To improve access to the DICEs and other health facilities, the AGYW during the FGDs suggested that BHEP should be issued with a kind of passport or identification card branded DREAMS. The PrEP champions, who are part of the PrEP users, should also be recognised in form of Information, Information and Education (IEC) materials like posters and flyers to make recruitment of other AGYW more effective. The PrEP IEC materials should speak to the AGYW and be in local translated languages. In the quote below, the peer educators cited the barriers to PrEP enrolment and continuation as inadequate youth friendly services, and lack of follow up post - enrolment in PrEP, and also provided reasons as to why the project succeeded in satisfying the needs of the AGYW.

The girls were also asked if aware that other partners providing services to the AGYW in the areas where they live, and they cited Hope World Wide Kenya (DREAMS Core) who provided education support to AGYW by paying school fees, training in business entrepreneurship to the AGYW and also training of parents to the AGYW. This was in addition to PrEP, a factor that was resonated with the peer educators.

The challenges in using PrEP are mainly scarcity of youth friendly services in most of the facilities and lack of follow up after enrolling AGYW on PrEP. The youth want to work with people who they can communicate with, and not feel judged. There are friendly service providers and safe spaces in all the DICEs for the AGYW to meet, talk and do fun activities like watching movies, for example SHUGA series and others. There were many services provided in the DICES including STI screening and treatment. This project embraced fun-filled activities such as the musical events that attracted many young people to participate and learn about HIV prevention including PrEP. The peer-led support groups and adherence meetings enabled young people to freely share their experiences on PrEP use and learn from one another. As the peer educators, we are the link between the AGYW and the program, and this makes it easier for the AGYW to take part continue being in the project - Peer Educators

As supporters of service provision, the peer educators faced challenges in performing their roles. Since PrEP was a new service, creating awareness needed numerous sessions both on their part, the AGYW and the community in general. This was further exacerbated by unavailability of IEC materials on PrEP for use during health education sessions. In addition, there were stockouts of drugs in the DICEs, and this hampered PrEP enrolment and continuation, and high mobility of AGYW, who sometimes relocated without informing the peer educators, giving rise to loss to follow up. The peer educators recommended availing other interventions such as scholarships to young people who would like to go back to school and exchange programs for the peer educators within BHESP and externally through other similar project to gain exposure to gain more knowledge and skills.

\section{Discussion}

A range of models for delivering PrEP have been proposed, including STI clinics, primary care clinics, and community-based organizations with links to clinics, each of which presents challenges. For example, while STI clinics serve a population at risk of HIV infection, most operate on a drop-in or urgent care basis and do not provide ongoing care and monitoring. Conversely, primary care clinics are experienced with ongoing care, but need to be able to identify people eligible for PrEP and offer risk reduction and adherence counselling [18]

BHESP innovation was informed by their experience in the PrEP demonstration project, which they participated in the year 2014-2016. The interventions proposed under this project targeting the AGYW were in keeping with the key concepts in HIV combination prevention, which prioritize sub-populations comprising among others, the young women at risk of infection. This is also in line with the goals of PEPFAR and DREAMS partnership, [11). and the guidelines on use of Antiretroviral Drugs for Treating and Preventing HIV infections in Kenya [180. The project reached three times the number envisaged at the proposal writing stage, which can be attributed to the diverse strategies that BHESP applied to reach the communities at large and the AGYW.

To inform general audience BHESP hosted 96 AGYW - led radio shows, in popular stations that are popular in areas where most of the vulnerable AGYW reside (Koch FM and Ghetto Radio). These stations have an average listenership of 150,000-200,000. Since PrEP was new in the country, these radio shows enabled the project to reach large numbers of listeners with information on PrEP and HIV in general, and address concerns from the audience to dispel the myths, perception and stigma towards PrEP. Use of peer-led musical events and social media, as well as peer educators and friends also enhanced overall reach and sensitisation on PrEP and demand for the services.

HIV counselling and testing services were offered both during the awareness raising activities and the DICEs as part of the PrEP screening exercise and during the three-months interval revisits, as is the requirement in the service delivery standards in country. This explains overachievement of target set at (10,.000). Most of those tested were AGYW, with a few males who turned for the service, either on their won or in the accompany of the AGYW. The positivity rate for all the women tested was less than 1\%, with the older women $25+$ years recording higher results than the overall overage and the AGYW. Even though the AGYW 15-19-year age bracket accounted for less than half the number of the total AGYW tested, the proportion testing positive was similar to the 20-24 years age category. positive results that were almost similar. Notably, all the 311 men tested for HIV obtained negative results and the HIV prevalence rates for the AGYW in the current study is lower than the national figures described in the literature review.

In line with the treatment protocols for HIV [18] those testing HIV positive were initiated on care and treatment within DICEs. Even though the project focus was the AGYW, BHESP provided services to all women who turned up for the 
services, as well as males, since according to the Kenya constitution (2010), access to health care services, including reproductive health care is a human right. A number of AGYW were also found to harbour the additional risk that have been shown to aggregate risk to HIV and adherence to PrEP. Nearly one in every five of the AGYW enrolled in PrEP had experienced some form the GBV and more so for the young women aged 20-24years; with six out of every ten reporting GBV. Violence and fear of violence has been shown to reduce adherence to HIV prevention technologies: pre-exposure prophylaxis (PrEP) for women not living with HIV [19] and post-exposure prophylaxis (PEP) for women possibly exposed to HIV [20]. BHESP in its strategy has a major component dealing with GBV and as can be seen in the results, over $60 \%$ of AGYW were linked to services where applicable, and these comprised of medical, psychosocial services. PrEP acceptance level was high, considering that about a half of those who were screened for PrEP and were enrolled in PrEP. About a third were young women, aged 20-24 years, as this category was the largest number enrolled into the project. A few women above 25 years and males were also initiated on PrEP; some of the males were the sex partners of AGYW, a factor that should be encouraged in future AGYW programming to enhance uptake and use of PrEP, thus effectiveness.

The adherence rate reported was higher than what the University of Washington reported in the just ended PrEP project in Kisumu (also under DREAMS)[21], probably due to the peer educators follow up mechanisms, which has an implication in sustainability. At any given time, the project is enrolling new AGYW in PrEP but concurrently providing continuing services for the old clients (refill/restart). However, the official indicator for PrEP captures only the new client (current) that were served in a particular reporting period. In which case, the continuation in PrEP is not officially reported. This has a negative implication in aligning the entire workload and services, as well as commodities consumed in each given period. One of the hindrances to data management has been the slow implementation of the electronic medical registry (EMR), which was part of the NASCOP's implementation plan for PrEP in the country. Once implemented it will automate the case management, entailing tracking PrEP continuation.

The satisfaction with the services offered during the project was very high across the service enrolment, service delivery and quality. The radio, musical shows, peer educators and friends were the most effective in raising awareness on PrEP. The FGDs showed that as expected, the AGYW were more attracted to activities that were fun and associated with musicians whom they looked up to as 'influencers', as opposed to the conventional methods use in community mobilisation. Football matches, which were adopted as the project progressed, also worked well in raising awareness in PrEP. It is worth to note that this was an innovation that was borrowed and adapted from TackleAfrica, one of the DREAMS innovation challenge IP linking males with HIV Services. Referral for PrEP from other implementing partners was the least effective, probably because there are several DREAMS core partners implementing PrEP in the same region and would sufficiently meet the demand for the service.

In-depth discussions with the AGYW and peer educators provided the reasons for the high satisfaction levels as the youth friendly nature of the services, specifically the closing hours, age of the service providers, service integration. The support groups that allowed the AGYW to freely interact and stay on PrEP, and the new knowledge on GBV \& how to deal with the issues, rated highly some of the other top factors that contributed to satisfaction. However, there is room for improvement in terms of information gap in terms of improving frequency of raising awareness since PrEP is new in the context and use of local language in the IEC materials to address to reduce the communication barriers. Since PrEP was new in Kenya, the Government spearheaded the production of IEC materials to ensure consistent messaging. As such the official materials became available much later after the PrEP program was launched. Adoption of the same to suit the AGYW is still work in progress, based on feedback gathered from the user, of which BHESP has been an active contributor, both at National and County government level. Generally, there was concurrence between the peer educators and the AGYW on factors pointing towards the high satisfaction scores.

Participation in the project had enabled the AGYW to seek services in a clinic, rather than buying over-the-counter medications, a common practice. The satisfaction survey revealed some gaps in the quality of services in delivering and use of the HIV self-testing kits, which even though was not a mainstream intervention in this project, requires more input, to ensure that the AGYW are well supported in making the service work with their male sex partners. Even though scores in PrEP continuation meetings generated high levels of satisfaction, there are indication that more effort is required to sustain the momentum that BHESP has generated. The action points are most likely tied to the barriers that hindered the AGYW from using PrEP, of which, time and side effects were each reported by half of the AGYW. Closely related to the low satisfaction level in HIV self-test kits is the partner support, with one in every five AGYW citing barriers on this front. Stock out of PrEP were also cited by the AGYW as a factor hindering continuation of PrEP. It is worth noting that PrEP is a new commodity in the country, and the national supply chain is yet to be well established. Consistent reporting of commodity consumption, as well as establishment of current and existing users, which is closely related to adherence to PrEP, will contribute to quality data, which will enable better forecasting and quantification of commodities.

Key recommendations from the AGYW and the peer educators involved; a) Open up the PrEP program to encompass other forms of support to the AGYW and the families, for instance economic empowerment, and educational support for the AGYW, many of whom wish to go back to school and further their academic qualifications; b) Exchange program for the peer educators, so that they can learn from other project sites and externally through other like-minded implementing partners.

\section{Conclusion}

The project has been successful in numerous ways as envisioned and learnt lessons in the process to improve the organisational current and future strategies. Demand creation, through raising awareness in ways that are responsive to the AGYW, enhanced uptake of PrEP and other HIV-related services. Adherence, a key component in PrEP efficacy is still a gap which requires further input and studies. Profiling and follow-up of AGYW is critical in defining and tracking 
adherence in PrEP to understand the characteristics of the AGYW and the intrinsic motivation in continued or discounted use of PrEP. The recommendation from the AGYW and peer educators on infusing of education subsidies specifically in the PrEP programs should be considered. Further innovations in bringing males closer to the services will also catalyse success factors in AGYW programming.

\section{Acknowledgements}

This activity was funded through a grant from the United States Department of State as part of the DREAMS Innovation Challenge, and managed by JSI Research \& Training Institute, Inc. (JSI). The opinions, findings, and conclusions stated herein are those of the authors and do not necessarily reflect those of the United States Department of State. The authors extend thanks to the Kenya government, along with the PEPFAR Coordinating Office in-country, for providing critical support and guidance to BHESP.

\section{References}

i. UNAIDS.

http://www.unaids.org/sites/default/files/media_asset/UNAIDS_HIV_prevention_among_adolescent_girls_and_y oung_women.pdf. Published 2016. Accessed August 19, 2019.

ii. National AIDS and STI Control Programme (2013). Kenya AIDS Indicator Survey 2012: Preliminary Report. Nairobi, Kenya

iii. Kinuthia J1, Drake AL, Matemo D, Richardson BA, Zeh C, Osborn L, Overbaugh J, McClelland RS, John-Stewart G (2013). HIV acquisition during pregnancy and postpartum is associated with genital Infections and partnership characteristics: A cohort study. J AIDS, 29(15); 2025-2033.

iv. World Health Organization (WHO). https://www.who.int/hiv/pub/prep/prep-implementation-tool/en/. Accessed August 22, 2019.

v. World Health Organization (WHO). http://apps.who.int/medicinedocs/documents/s22247en/s22247en.pdf. Accessed August 19, 2019.

vi. San Francisco Department of Public Health, Population Health Division. https://www.sfdph.org/dph/files/reports/RptsHIVAIDS/Annual-Report-2016-20170831.pdf Accessed August 20, 2019.

vii. Kurth AE, Celum C, Baeten JM, Vermund SH, Wasserheit JN (2011). Combination HIV prevention: Significance, challenges, and opportunities. J Curr HIV/AIDS Rep, 8(1):62-72.

viii. UNAIDS Prevention Gap Report. http://www.unaids.org/sites/default/files/media_asset/2016-prevention-gapreport_en.pdf. Accessed August 25, 2019.

ix. Centers for Disease Control and Prevention (CDC). https://www.cdc.gov/hiv/basics/prep.html. Accessed March 19, 2019

x. Baeten JM, Donnell D, Ndase P, Mugo NR, Campbell JD, Wangisi J, Tappero JW, Bukusi EA (2012). Antiretroviral prophylaxis for HIV-1 prevention among heterosexual men and women. J New Eng Med,367(5):399-410

xi. https://www.usaid.gov/global-health/health-areas/hiv-and-aids/technical-areas/dreams. Accessed March 18, 2019

xii. Population Council. www.popcouncil.org/uploads/pdfs/2016HIV_PrEPGuidanceForAGYW.pdf. Accessed in Accessed March 22, 2019

xiii. Thomson KA, Baeten JM, Mugo NR, Bekker LG, Celum CL, Heffron R (2016). Tenofovir-based oral preexposure prophylaxis prevents HIV infection among women. J Curr Opin HIV AIDS, 11(1):18-26.

xiv. Cohen SE et al (2014). Implementation of PrEP in STD Clinics: High Uptake and Drug Detection Among MSM in the Demonstration Project. 21st Conference on Retroviruses and Opportunistic Infections (CROI), abstract 954. http://www.croiconference.org/sessions/implementation-prep-std-clinics-high-uptake-and-drug-detectionamong-msm-demo-project. Accessed in July 13, 2019

xv. Roberts ST, Haberer J, Celum C, et al (2016). Intimate partner violence and adherence to HIV Pre-exposure Prophylaxis (PrEP) in African women in HIV serodiscordant relationships: A Prospective cohort study. J Acquir Immune Defic Syndr, 73(3):313-322.

xvi. Haire, BH (2015). Preexposure prophylaxis-related stigma: strategies to improve uptake and adherence - a narrative review.J HIV/AIDS Research and Palliative Care,7:241-249.

xvii. National AIDS and STI Control Programme (2016). Guidelines on Use of Antiretroviral Drugs for Treating and Preventing HIV infection in Kenya, Nairobi, Kenya.

xviii. Norton WE, Larson RS, Dearing JW (2013). Primary care and public health partnerships for implementing preexposure prophylaxis. Journal of American Preventive Medicine,44: 77-79

xix. Roberts ST, Haberer J, Celum C, Mugo N, Ware NC, Cohen CR, Tappero JW, Kiarie J, Ronald A, Mujugira A, Tumwesigye E, Were E, Irungu E, Baeten JM (2016). Intimate partner violence and adherence to HIV pre-exposure prophylaxis (PrEP) in African women in HIV serodiscordant relationships: A prospective cohort study. J Acquir Immune Defic Syndr, 73(3): 313-322.

xx. Ford N, Irvine C, Shubber Z, Baggaley R, Beanland R, Vitoria M, Doherty M, Mills EJ, Calmy A (2014). Adherence to HIV post-exposure prophylaxis: A systematic review and meta-analysis, J AIDS, 28: (18):2721-2727

xxi. Kenneth M, Kinuthia J, Pintye J, Dettinger J, Emily B, Felix A, Lagat H, Joseph S, John-Stewart G, Jared B. Persistence with PrEP use among young women initiating PrEP in maternal child health and family planning clinics in Kenya. 
Conference on Retroviruses and Opportunistic Infections (CROI). March 4-7, 2019. Seattle, YWA, USA. Abstract \#0993

xxii. http://www.croiconference.org/sessions/persistence-prep-use-african-adolescents-and-young-womeninitiating-prep

xxiii. Accessed in August 19, 2019 